\title{
GRAPHIC CORRELATION AS A TOOL FOR SEQUENCE STRATIGRAPHIC ANALYSIS
}

STEIN*, Jeffrey A., GAMBER, James H., LANE, H. Richard, Amoco Explor. \& Prod. Technology, P.O. Box 3092, Houston, TX 77253, U.S.A.; NEAL, Jack E., Exxon Production Research Company, P.O.Box 2189, Houston, TX 77252-2189

The management of biostratigraphic data by graphic correlation and composite standard development offers many distinct advantages in sequence stratigraphic applications. In its highest form, a composite standard is a multi-disciplinary synthesis of fossil and physical-event occurrences, defined quantitatively with reference to a chronostratigraphic scale. Fossil ranges in the composite standard represent both wellknown index taxa and zonal markers, as well as underutilized, and often numerous, accessory taxa. Compared to conventional zonations, a composite standard provides increased stratigraphic resolution, often critical to delimiting paleontologically-defined depositional sequences (biothems) comparable to seismic-based stratigraphic interpretations. Chronostratigraphic interpretations based on the composite standard may be presented in simple, graphic correlation $\mathrm{X} / \mathrm{Y}$ plots that communicate age correlations visually in a consistent format.

The graphs obviate the highly specialized and jargonized zonal nomenclatures traditionally used to convey age correlations. More importantly, graphic correlation displays provide very clear indications of the hiatuses that characterize sequence boundaries. The composite standard (scale on $\mathrm{x}$-axis) provides relatively complete chronostratigraphic representation; hiatuses in the comparison section (y-axis) are defined by horizontal terraces that offset the lines of correlation. The composite standard scale measures the time duration of each hiatus. The same scale may be related to rates of rock accumulation for the lines of correlation. In this manner, the graphic display provides a quantified representation of chronostratigraphic architecture upon which reliable sequence stratigraphic analyses can be developed. 